\title{
LA NATURALEZA JURÌDICA DE LA MULTIPROPIEDAD
}

\author{
Rojas Ulloa, Milushka ${ }^{44}$
}

SUMARIO: 1. Introducción. - 2. Caracteres y elementos básicos. - 3. Naturaleza jurídica de la multipropiedad. - 4. Análisis y críticas. - 5. Nuestra propuesta. -6 . La multipropiedad en el Perú

\section{Introducción}

La Multipropiedad como una novedosa práctica de adquirir un bien inmueble, es una institución mediante el cual se determina la prerrogativa de usar y disfrutar de forma exclusiva y durante un periodo de tiempo determinado, un alojamiento amoblado con sus respectivos servicios complementarios, es decir de instalaciones deportivas, piscinas, gimnasios, salas de entretenimiento informático, y todo aquello que a la familia le permita recrearse de una manera sana y saludable.

Sin embargo, sabemos que no todos disponemos de los medios necesarios para sufragar estos costos, o si teniendo esta posibilidad, resulta oneroso adquirir un inmueble para utilizarlo sólo por determinados periodos al año, quedando la mayor parte del tiempo desocupado y acarreando en todo momento gastos de mantenimiento y conservación. Por ello, refuerza la importancia de este sistema, el hecho que, no solamente esté dirigido a las minorías de mayores recursos económicos, sino sobre todo, esta figura jurídica ha sido creada pensando en todas las clases sociales, por sus accesibles costos de adquisición, permitiendo a los interesados en sus momentos de libre disposición, acceder al turismo vacacional a través de la multipropiedad.

Mas allá de lo que establece nuestra legislación respecto de la propiedad, considerada como el poder jurídico que permite usar, disfrutar, disponer y reivindicar un bien, derecho que debe ejercerse en armonía con el interés social y dentro de los límites de la ley, encontramos que un bien inmueble, puede aprovecharse no sólo teniendo en cuenta el espacio que ocupa, sino también, considerando un elemento adicional, que es el factor tiempo.

${ }^{44}$ Doctora en Derecho y Ciencia Política UNMSM, Docente de Pre y Post Grado en Universidad de San Martín de Porres; Universidad Nacional Federico Villarreal; Universidad José Carlos Mariátegui; Universidad San Luis Gonzaga de Ica; Universidad Hermilio Valdizán de Huánuco; Universidad Privada de Tacna; Universidad Nacional de Piura. 
A través de los años, los empresarios han tratado de generar diversas actividades económicas que les produzcan mayores márgenes de rentabilidad a sus inversiones y que obviamente éstas, tengan la aceptación de los usuarios, quienes finalmente son los que certifican el éxito o fracaso de dicha actividad. En virtud de ello, fueron los grandes inversionistas, quienes han ideado la manera de adquirir un bien en forma proporcional al tiempo de descanso vacacional, nos referimos a la Multipropiedad, conocida en el mundo anglosajón como Time-Sharing, que significa Tiempo Compartido.

Dado el empeño que tiene el Estado en la promoción del turismo en todas las modalidades de desarrollo existentes, la Multipropiedad abre un nuevo concepto en el aprovechamiento de la capacidad turística del país, por lo que considero que ésta institución jurídica merece un estudio especial, así como la necesidad de regular sus alcances, a fin de poder actuar en igualdad de condiciones con los demás países en materia de turismo.

Es preciso establecer la naturaleza jurídica de la multipropiedad para darle viabilidad a este nuevo sistema, tratando que se desarrolle a cabalidad, y se brinde seguridad a ambas partes contratantes; asimismo, es necesario establecer que este novedoso sistema cuenta con elementos y características que lo hacen diferente de otras instituciones ya reguladas por nuestro derecho, no pudiendo incorporarse a ninguna de ellas, puesto que se desnaturalizaría su esencia.

En el Perú en cambio, se ha legislado la institución de tiempo compartido a través del D.L. $\mathrm{N}^{\circ} 706$ como un supuesto de copropiedad, adoptando la teoría de la aplicación analógica en la celebración de estos contratos, por cuanto considera a la copropiedad como la figura tipificada más afín. No por ello, deja de constituir un contrato atípico que no cuenta con una regulación apropiada para tal efecto.

En Europa, Estados Unidos y en algunos países Sudamericanos se habla de ésta institución y de su importancia, sin precisar cual es su naturaleza jurídica, es decir si corresponde a un derecho real, o un derecho personal; asumiendo en consecuencia diversas modalidades e inclusive equiparándolo con algunas figuras legales ya reguladas en el derecho interno de cada país.

\section{Caracteres y elementos básicos}


La racionalidad del sistema es concreta, si anualmente se dispone de un tiempo limitado para el descanso y se desea disfrutar de ese periodo anual en un lugar que reúna los requisitos para tal descanso, entonces ¿Por qué no adquirir un inmueble en el lugar que se prefiera, realizando una inversión directamente proporcional al tiempo de descanso anual del que se dispone? Vayamos a analizar cada uno de éstos elementos básicos:

2.1. Inversión directamente proporcional al tiempo correspondiente al descanso vacacional.

Este es un aspecto fundamental de la propuesta del sistema ya que no sólo significa la posibilidad de acudir a un lugar turístico a disfrutar de un periodo específico al año, sino que establece una proporcionalidad económica entre los medios económicos de que se dispone y el tiempo de duración del descanso vacacional. No se mantiene un inmueble cerrado la mayor parte del tiempo con todos los gastos que acarrea su mantenimiento para disfrutarlo en un periodo muy corto. En el monto a pagar por un periodo determinado influyen circunstancias externas como: el lugar de ubicación del bien, la afluencia de la gente en determinadas épocas del año, el elemento climático al periodo del cual se es titular cuando se está en temporada.

2.2. Uso exclusivo del bien durante el respectivo período de ocupación

Lo que se busca con éste sistema es que el titular tiene la exclusividad en el periodo de tiempo correspondiente; es otro elemento esencial de éste sistema y que lo hace atractivo.

\subsection{Disfrute de diversos servicios necesarios y propios del sistema}

Se debe destacar que la Multipropiedad inmobiliaria se halla configurada por una serie de servicios que forman parte del sistema y a al vez, necesarios para que éste funcione perfectamente. Así tenemos, por ejemplo, los servicios de mucama y mantenimiento de la unidad y el servicio de vigilancia. Además de zonas comunes o de uso compartido como patios, piscinas, canchas diversas, saunas, etc.

2.4. Perpetuidad del Sistema de Multipropiedad en el inmueble preafectado y perpetuidad del derecho.

Empezaremos el desarrollo de éste punto refiriéndonos a la aludida pre-afectación del inmueble. 
De lo que se trata es que el inmueble sujeto a éste sistema sea previamente afectado y que así conste en el Registro de Propiedad Inmueble, como un bien sobre el cual únicamente pueden recaer derechos de Multipropiedad. Tal pre-afectación tiene una serie de consecuencias jurídicas importantes como la protección a los terceros en el sentido que al comprar dentro del sistema de Multipropiedad su tiempo de ocupación se halla delimitado a un lapso determinado del año.

Sin embargo, lo más resaltante en éste punto, es que en la Multipropiedad, la preafectación significa que a partir de ese momento el inmueble entra a un sistema especial, cuya esencia es la perpetuidad del mismo. Esto no ocurre en la co-propiedad donde su esencia está determinada por la transitoriedad de la misma y bastaría la decisión de uno sólo de los co-propietarios de solicitar la partición para que el inmueble se divida.

La perpetuidad consiste en que el titular puede indefinidamente usar, disfrutar y disponer de las facultades que su derecho le otorga, durante su lapso de tiempo.

2.5. Posibilidad de transmitir el periodo de ocupación en el inmueble pre-afectado al sistema, Mortis causa e inter vivos.

La Multipropiedad plantea la posibilidad que quién sea titular de ese derecho tenga la facultad de transmitir el dominio del bien, al igual que éste también podrá gravarlo, disponer del uso o el disfrute existiendo en éste caso un plazo de duración para que tales atributos regresen a su propietario.

El Multipropietario entonces debe tener facultad de transmitir su derecho inter vivos, sea por medio de un contrato de compra-venta o una donación y mortis causa, lo cual significa que al morir el inmueble entrará a la masa hereditaria como un bien más, pudiendo usarlos si son más de uno o venderlo y repartirse el dinero producto de la venta. Toda transacción siempre deberá estar referida al módulo temporal que delimita al objeto. El espacio y el tiempo forman una unidad indelegable e inalterable.

2.6. Posibilidad de intercambiar el periodo de ocupación respectivo por otro distinto complejo turístico, interno o internacional

El Intercambio Vacacional, consiste en la formación de consorcios de Multipropiedad a nivel de cada país adheridos a un sistema de intercambio determinado, de características similares desde todo punto de vista, incluyendo la división temporal. Mediante este sistema se permite al multipropietario la posibilidad de disfrutar del 
periodo vacacional en otros lugares, a través de las denominadas "bolsas de Intercambio", con lo cual acceden a otras zonas, sin necesidad de invertir en adquirir otro derecho de Multipropiedad en otro lugar.

Desde el punto de vista legal, se trataría de un comodato, mediante el cual dos titulares de diferentes objetos, se prestan mutuamente los mismos para ser devueltos recíprocamente una vez vencido el lapso que da forma a sus respectivos objetos. Cabe señalar que el intercambio será factible entre complejos que presten servicios similares, los mismos que conformarán las denominadas cadenas o bolsa de intercambio sea interna o internacional.

\section{Naturaleza jurídica de la multipropiedad}

\subsection{Como derecho}

Llamada también Multipropiedad Societaria, donde el patrimonio Social es el complejo inmobiliario turístico, mediante el cual cada socio tiene el derecho al disfrute periódico durante un periodo anual; obligándose el socio al pago de una cuota de mantenimiento de las unidades inmobiliarias y la manutención de las áreas y servicios comunes.

\section{Desventajas}

- No puede el Multipropietario disponer de su propiedad sin autorización de la sociedad, su derecho no es perpetuo ya que estará sujeto el plazo de duración de la sociedad existiendo siempre inseguridad económica ante eventual quiebra de la misma.

- Las sociedades tienen por objeto fundamental obtener utilidades, lo cual no se da en la Multipropiedad en que anualmente lo único que se posee es un derecho de goce o disfrute sobre los inmuebles de la sociedad. Otros autores opinan que el lucro no debe interpretarse literalmente sino que también puede traslucirse en bienes de goce.

- La disponibilidad de la utilización o uso de los bienes que conforman el patrimonio de la sociedad es en beneficio personal de cada socio y para su goce exclusivo. Sin embargo, la Multipropiedad accionariada se basa justamente en que la sociedad otorga el goce individual de su patrimonio a favor de sus socios.

- Respecto a la vida de la sociedad, ésta se liquida, vendiendo todos los inmuebles y entregando a cada socio una parte proporcional a su participación en dinero

Resumiendo, los socios sólo mantiene una relación obligacional y personal más no real; esta forma es difundida en Italia y Francia. Estas objeciones se pueden dejar de lado si se visualiza la Multipropiedad como derecho personal dentro del marco de una sociedad atípica no lucrativa o persona jurídica típica sin fines de lucro como las asociaciones, mutuales o cooperativas aunque con ciertas limitaciones.

\subsection{Como derecho real}


No es un derecho real propiamente dicho ya que para ello se requeriría modificar la estructura de los numerus clausus de los derechos reales, que impera en nuestro ordenamiento jurídico nacional, agregando la Multipropiedad como un nuevo derecho real dentro del ámbito del derecho propiedad, por ser una figura que reúne las cualidades y particularidades que exige una regulación propia, alejando al instituto de la propiedad, su carácter individualista, propia del derecho romano, para convertirse en una institución basada en el bienestar social ${ }^{45}$, porque permite que un mismo bien pueda ser usado y gozado por una pluralidad de personas, de acuerdo al turno establecido, siendo dicha función social de la propiedad, la que pregona la doctrina moderna.

Mediante el sistema del numerus clausus, ningún particular puede crear más derechos reales que aquellos establecidos por la ley, contrario a ello es el sistema del numerus apertus, donde los particulares si pueden crear derechos reales distintos de aquellos establecidos o tipificados por la ley, llamados derechos reales atípicos, ello se da, tomando como base el principio de la autonomía de la voluntad.

El sistema del numerus clausus de los derechos reales, se basa en la idea que la constitución de derechos reales es una cuestión que no presenta únicamente un interés privado, sino que afecta también a los intereses de terceros y en definitiva al orden público, siendo por tanto la ley quien debe crearlos. ${ }^{46}$

Nuestro Código Civil recoge en el Art. 881, el principio del numerus clausus o número cerrado de los derechos reales, al establecer que "Son derechos reales los regulados en éste Libro y otras leyes". Por sus especiales características, la multipropiedad, no podrá ubicarse en ninguna de las modalidades conocidas del dominio sino como un nuevo derecho real sobre cosa propia. Por este aspecto y adelantándonos a nuestras conclusiones, podemos afirmar que es necesaria la dación de una Ley para incluir a la Multipropiedad dentro de los derechos reales.

Nos preguntaremos si es posible individualizar objetos jurídicos a través de la conjunción de dos factores: el espacial y el temporal; la respuesta es afirmativa ya que

${ }^{45}$ La propiedad es el poder jurídico más amplio que se puede ejercer sobre un bien. Según el Art. 923 del CC.1984 "La propiedad es el poder jurídico que permite usar, disfrutar, disponer y reinvindicar un bien. Debe ejercerse en armonía con el interés social y dentro de los límites de la ley” Asimismo nuestra Constitución establece en su Art. 70:”El derecho de propiedad es inviolable. El Estado lo garantiza. Se ejerce en armonía con el bien común y dentro de los límites de ley. A nadie puede privarse de su propiedad sino, exclusivamente, por causa de seguridad nacional o necesidad pública, declarada por ley, y previo pago en efectivo de indemnización justipreciada que incluya compensación por el eventual perjuicio. Hay acción ante el Poder Judicial para contestar el valor de la propiedad que el Estado haya señalado en el procedimiento expropiatorio"

46 Allendesalazar Ormaechea, Luis, El Time-Sharing. Su configuración jurídica Tributaria en España, Álvarez Arza. Madrid 1987, p.72. 
sobre el principio de autonomía de la voluntad, y no encontrando ninguna norma que prohíba que un sujeto realice la división temporal de la cosa que ostenta en propiedad, debe ser posible realizarla.

Tengo la convicción que su función social es digna de protección, en cuanto que es más beneficiosa que la propiedad de uno sólo, el dar más beneficios y utilidades a más personas.

\subsubsection{Semejanzas y diferencias con el Usufructo}

Son varias las empresas propietarias de los complejos turísticos que celebran contratos de multipropiedad, concediéndoles un derecho de usufructo a los adquirentes del sistema. Es decir, se concede el derecho a la utilización y disfrute de un inmueble durante un concreto periodo al año, mediante la emisión de certificados de vacaciones o certificados de Time-Share.

De acuerdo a lo normado en nuestro derecho positivo, se trataría de un usufructo múltiple, por ser atribuido a varias personas, y de disfrute sucesivo, ya que entran al goce de la cosa uno después del otro, de acuerdo al turno pre-establecido.

El Art. 999 del CC. establece que el usufructo nos da el derecho a usar y disfrutar temporalmente de un bien ajeno; ello implica que se trata de un derecho real restringido, puesto que carece de la facultad de disposición contenida en el derecho real de propiedad. ${ }^{47}$

Como lo señala el Dr. Allendezalazar:

"A través del usufructo, como derecho limitativo del dominio, se produce una división y en consecuencia un distinto destino de estas facultades; el nudo propietario conserva las facultades de disposición, mientras que el goce, el disfrute, el aprovechamiento de la cosa pasan al usufructuario; es decir, en el usufructo las dos facultades esenciales que integran el dominio se hallan separadas, perteneciendo a una persona el derecho de disponer y a otra distinta el de gozar o, ...disfrutar." ${ }^{48}$

${ }^{47}$ Por el usufructo la propiedad se desmembra, pues el usufructuario adquiere la facultad de gozar la cosa, mientras el propietario conserva el derecho de propiedad disminuido en la facultad de gozarla. Pueden excluirse del usufructo determinados provechos y utilidades, pudiendo recaer sobre toda clase de bienes no consumibles, salvo lo dispuesto en los artt. 1018 y 1020 del CC.1984. Se caracteriza por ser un derecho real, permite al usufructuario usar y gozar de la cosa; recae sobre bien ajeno; no debe conllevar ninguna modificación sustancial del bien o de su uso a fin de que conservándolas, devolverlas al propietario, extinguido el derecho del usufructuario. El usufructo se puede constituir por ley, por contrato o por acto unilateral, véase: VÁSQUEZ Ríos, Alberto. Ob.cit., pp. 216-220.

${ }^{48}$ Allendes AlAZAR, Luis. Op. cit. p. 76. 
Partiendo de éste punto de vista, en que el usufructuario sólo podrá disponer del goce de la cosa, pero no de la cosa en si misma, al Multipropietario que ostenta un certificado de vacaciones, no podrá disponer del inmueble sobre el que recae un derecho de usufructo, es decir no podrá gravarlo o enajenarlo; lo único que tendrá derecho es a ceder o traspasar libremente los derechos y deberes que se derivan de dicho certificado.

Sin embargo, el usufructo tal como está regulado en nuestro Código Civil., contiene elementos que lo diferencian de la figura de la multipropiedad; tal es el caso que el usufructo es un derecho vitalicio, extinguiéndose con la muerte del usufructuario, a diferencia que el derecho del multipropietario es perpetuo y transmisible mortis causa o acto inter vivos.

Esta modalidad adoptada por los promotores, tiene mucha acogida, ya que éstos conceden el derecho de usufructo por un plazo fijo, vencido el cual el propietario que ostenta el derecho de propiedad pero limitado al uso y disfrute, vuelve a recuperarlo, haciendo más rentable ésta modalidad, al no conceder también el derecho a disponer del inmueble, como sería mediante un contrato de compra-venta.

Nuestro código establece la obligación del usufructuario a prestar la garantía señalada en el título constitutivo de su derecho o la que ordene el juez, cuando éste encuentre que puede peligrar el derecho del propietario. En la multipropiedad no existe obligación previa de prestar fianza, para usar y disfrutar del bien objeto del contrato, a menos que el contrato lo contemple, siendo la excepción.

Todas éstas características del usufructo nos llevan a considerarla como una figura que no acoge en su totalidad a la multipropiedad, teniendo ésta última mayores facultades y siendo un derecho real más completo.

\subsubsection{Semejanzas y diferencias con el derecho de Habitación}

Desde el momento en que existe un propietario de la unidad inmobiliaria y una pluralidad de consumidores, en la calidad de "huéspedes" que mantienen su derecho en base al contrato de cesión de uso podríamos decir que hay hospedaje.

Nuestro Código Civil en su Art. 1027, establece que el derecho de habitación es el derecho de usar o servirse de una casa o parte de ella, para servir de morada. También se establece que éstos derechos se extienden a la familia del usuario, salvo disposición distinta, no pudiendo ser materia de ningún acto jurídico, salvo la consolidación. ${ }^{49}$

49 CC.1984: Art. 1027.- Cuando el derecho de uso recae sobre una casa o parte de ella para servir de morada, se estima constituido el derecho de habitación. 
De acuerdo a las características señaladas, quedaría descartada la inclusión de la multipropiedad, como un supuesto de habitación, por ser un derecho de carácter vitalicio, eliminándose la posible transmisión mortis causa de su derecho ${ }^{50}$. Incluso, se hace más grande la diferencia, al quedar determinado por la ley, que se prohíbe cualquier transmisión inter vivos. ${ }^{51}$

Por ello, son claras las diferencias que separan ambas figuras, ya que como lo señalara en el capítulo anterior, al hablar de las características de la multipropiedad, se trata de un derecho transmisible por acto inter vivos o mortis causa. ${ }^{52}$

Si bien es cierto que en Portugal han regulado la Multipropiedad como un derecho de habitación periódica, han tenido que crear un nuevo derecho real, en el que desaparezcan esas características de intransmisibilidad propias del derecho de habitación, típico en la mayoría de legislaciones que tienen un Código Civil. Sin embargo, ésta figura no ha sido seguida por otras legislaciones por no ajustarse a las características propias del derecho de multipropiedad y por encontrar solución en otras bases jurídicas. ${ }^{53}$

\subsubsection{Semejanzas y Diferencias con la Copropiedad}

Es precisamente con ésta figura jurídica, con la que en gran medida se trata de equiparar a la Multipropiedad, arguyendo que es la que mejor se adapta al funcionamiento y naturaleza de éste sistema, aunque sabiendo que existen objeciones técnicas, las cuales se pueden salvar mediante una reforma legislativa de la copropiedad.

${ }^{50}$ Art. 1028.- "Los derechos de uso y habitación se extienden a la familia del usuario, salvo disposición distinta"

Art. 1029.- "Los derechos de uso y habitación no pueden ser materia de ningún acto jurídico, salvo la consolidación."

${ }^{51}$ Transmisión mortis causa, está constituida por aquellos derechos que se pueden transmitir para después de la muerte del causante.

${ }^{52}$ Los actos inter vivos son aquellos cuyos efectos jurídicos se producen en vida de quienes lo celebran, Ejm. Un contrato, la constitución de una sociedad, el reconocimiento de una deuda; mientras los actos mortis causa, son aquellos cuyos efectos jurídicos se producen para después de la muerte del causante Ejem. El testamento. La multipropiedad se puede transmitir por medio de un contrato (acto inter vivos) pero también se puede transmitir por testamento (acto mortis causa), formando parte de la masa hereditaria.

${ }^{53}$ Decreto Ley 355-81 (Portugal), regula a la Multipropiedad como un derecho real de habitación periódica. En la práctica equivale a un régimen de propiedad dividida pero ya no por pisos sino por espacios temporales o cuotas de tiempo. Este nuevo derecho real de habitación periódica, tiene las siguientes características: perpetuidad del derecho, transmisión mortis-causa e inter vivos, posibilidad de intercambio vacacional, uso y goce exclusivo por un lapso anual y, la incorporación del derecho en un certificado inmobiliario, el mismo que permitirá la enajenación de aquél con el simple endoso de éste. 
Según lo establecido en el Art. 969 de nuestro Código Civil, habrá Copropiedad cuando un bien pertenece por cuotas ideales a dos o más personas. Es decir, la copropiedad es el derecho real de propiedad perteneciente a varias personas, las cuales ejercen sus derechos simultáneamente de acuerdo a su cuota, sobre un bien mueble o inmueble que no está dividido.

Nuestro Código, se basa en el derecho romano clásico, al establecer dentro de su regulación, la transitoriedad del derecho de copropiedad, como consecuencia de la preeminencia del derecho del individuo frente al grupo, pudiendo, cualesquiera de los copropietarios, en cualquier momento, pedir la división.

Sin embargo, se admite que la división del bien, pueda ser diferida en el tiempo, al establecer en el Art. 993 del Código Civil, que los copropietarios pueden celebrar pacto de indivisión por un plazo no mayor de cuatro años y renovarlo todas las veces que lo juzguen conveniente; pero no podría entenderse que la indivisión del bien es a perpetuidad, puesto que conllevaría a la desnaturalización del derecho mismo de copropiedad, violándose el precepto de orden público imperativo que regula a los derechos reales.

Habiendo desarrollado las características más resaltantes de ésta figura, podemos argumentar, que el escollo principal encontrado, para adaptar la figura de la Multipropiedad a la copropiedad es el derecho de cada comunero a pedir la partición del bien cuando crea conveniente, lo que traería como consecuencia que el sistema mantenga una constante inestabilidad y no exista una seguridad de parte de los adquirentes, para usar y disfrutar de su derecho a perpetuidad. ${ }^{54}$

Otro inconveniente, es que en la copropiedad, cualquier comunero puede hacer uso del derecho de retracto, y si cualquier multipropietario en el caso de enajenarse por alguno su participación en el inmueble objeto de multipropiedad, pudiera ejercer el derecho de retracto sobre la participación enajenada, traería como consecuencia la concentración de la propiedad en manos de pocos, no siendo su finalidad socioeconómica, ya que la multipropiedad lo que busca es la socialización de la propiedad, para que ésta sea aprovechada por más personas, durante diversos periodos de tiempo al año. ${ }^{55}$

${ }^{54}$ Para algunos autores la copropiedad debe ser pasajera y transitoria, porque riñe con el carácter exclusivo y excluyente del derecho de propiedad; por cuanto el sujeto del derecho no es un individuo, sino dos o más, que lo ejercen simultáneamente; sin embargo, cada copropietario es el señor de una cuota ideal de la cosa. Ver: VÁsQuez Ríos, Alberto. Ob.cit. p.188)

${ }^{55}$ CC.1984 Art. 989.- "Los copropietarios tienen el derecho de preferencia para evitar la subasta de que trata el Art. 988 y adquirir su propiedad, pagando en dinero el precio de la tasación en las partes que correspondan a los demás copartícipes.” Art. 993.- "Los copropietarios pueden celebrar pacto de indivisión por un plazo no mayor de cuatro años y renovarlo todas las 
Dentro de las diferencias encontradas entre ambas figuras puedo señalar entre las más resaltantes, las siguientes: en la copropiedad el inmueble se encuentra dividido espacialmente, mientras en la Multipropiedad la división es espacial y temporal; en la Copropiedad existe una pluralidad de titulares con derecho de propiedad sobre todo el inmueble, todo el tiempo, en la Multipropiedad el adquirente es titular exclusivo sobre el inmueble delimitado a un periodo anual; la copropiedad es transitoria y posible de partición, mientras que la Multipropiedad es a perpetuidad, no existiendo la partición; en la copropiedad el uso exclusivo del bien obliga a indemnizar a los demás copropietarios, en la multipropiedad el uso exclusivo es esencial y no existe obligación de indemnizar a nadie; y en la copropiedad existe el derecho de acrecer, lo que no se da en la Multipropiedad.

Vemos, pues, una serie de diferencias que hacen casi imposible regular a la multipropiedad como un supuesto de copropiedad, ya que la multipropiedad tiene elementos y características que lo convierten en una figura autónoma, de necesaria regulación y que no se puede equiparar a ningún otro instituto jurídico ya regulado en nuestro Código Civil.

\subsubsection{Semejanzas y diferencias con la Propiedad Horizontal}

En España, una parte de la doctrina considera a la Multipropiedad, como un supuesto de Propiedad Horizontal, pero atípica, por contener excepciones o especialidades diferentes al régimen de propiedad horizontal.

La Multipropiedad, fue conocida en España, como propiedad horizontal por períodos, la cual se caracteriza por el hecho que los pisos situados en un inmueble sujeto al régimen de propiedad horizontal son vendidos a diferentes personas, dado que la utilización de cada uno de éstos sólo van a poder tener lugar durante un determinado espacio de tiempo de cada año.

Se diría que coexisten sobre un mismo piso dos regímenes jurídicos: el de propiedad horizontal, del piso en relación a todos los demás pisos y elementos comunes; y el de comunidad, entre los diferentes titulares del derecho de propiedad con un límite temporal con relación al uso y disfrute sobre el mismo piso. ${ }^{56}$

veces que lo juzguen conveniente. El plazo de indivisión que no consigne plazo se presume que es por cuatro años...”

56 Aunque hoy es conocida como régimen de unidades inmobiliarias de propiedad exclusiva y propiedad común (Ley 27157), podemos definirla como una modalidad de propiedad en la que coexisten bienes de dominio exclusivo y bienes de propiedad común. Se trata de un régimen jurídico que supone la existencia de una edificación o conjunto de edificaciones integradas por secciones inmobiliarias de dominio exclusivo pertenecientes a distintos 
Esta forma de visualizar a la multipropiedad, para muchos autores debe ser descartado, ya que la copropiedad importa adquisición conjunta del bien, mientras que en la multipropiedad la adquisición se lleva a cabo en forma independiente por cada adquirente, sin que haya previo concierto entre ellos; cada titular, durante su respectivo período de uso, ostenta un derecho de disfrute pleno, sin tener que compartir en el tiempo ese derecho con los demás cotitulares; y los gastos a cargo de los multipropietarios se refieren a su cuota -tiempo.

La Propiedad Horizontal contiene dos derechos regulados por nuestro ordenamiento jurídico: es producto de la suma de una propiedad privativa y de una copropiedad. Mientras que la Multipropiedad incluye un factor esencial, básico y diferenciador, que el factor tiempo.

Para el Dr. Pedro Munar Bernat, en el sistema multipropietario, no hay una adición de la propiedad individual y una copropiedad, sino que aparece un nuevo derecho subjetivo que hasta el momento no había sido conocido por el ordenamiento jurídico, al tratarse un tiempo de uso sobre un inmueble como objeto de la propiedad privativa. Las normas referidas a los órganos de administración de la propiedad horizontal, parecen poco adecuadas para aplicarse a la multipropiedad, puesto que en ella el epicentro está formado por la Junta de Propietarios, quien es quien nombra a su administrador. En la Multipropiedad, en cambio, tal esquema está abocado al fracaso, debido a que si es difícil que todos los copropietarios de un mismo piso puedan reunirse, más lo será conseguir que lo hagan todos los multipropietarios, cuyo derecho lo disfrutan en diversos tiempos al año. ${ }^{5}$

\subsubsection{La Propiedad Temporal y la Propiedad Dividida}

La tendencia actual de la doctrina, es la de considerar que la perpetuidad no es ya, una característica esencial de la propiedad; como por ejemplo la propiedad intelectual e

propietarios y bienes y servicios de dominio común, que cuentan con un reglamento interno y una junta de propietarios. Esta pluralidad de titulares es lo que esencialmente caracteriza a la propiedad horizontal.

Nuestra legislación acerca de la naturaleza jurídica nos señala que es una modalidad especial o peculiar de la propiedad, en la que junta a la propiedad exclusiva (de los pisos, departamentos o secciones) existe la copropiedad forzosa (de los elementos comunes). No se trata de la copropiedad o condominio, porque éste requiere que no haya propiedad global o materializada, sino una participación en el todo, fijada aritméticamente. En la propiedad horizontal, en cambio con derecho absoluto, por consiguiente podrá arrendarlo, hipotecarlo, venderlo y en general gravarlos libremente. Como puede advertirse son dos los elementos configurativos de la propiedad horizontal: $a$ ) la propiedad sobre las zonas de dominio exclusivo, y $b$ ) la copropiedad sobre los bienes de dominio y uso común.

${ }^{57}$ MunAr Bernat, Pedro. Op. cit. pp. 121-122 
industrial, la propiedad sometida a condición resolutoria. Es admisible una propiedad perpetua, no siendo incompatible con la admisibilidad de una propiedad temporal, en la que podría incluirse a la multipropiedad.

La doctrina Italiana, ha intentado explicar la naturaleza jurídica de la multipropiedad en basa a la idea de la propiedad temporal; sin embargo consideramos que no debe equipararse ambas figuras, ya que, la temporalidad a que hace referencia la multipropiedad, no se refiere a la duración del derecho en sí, sino a la periodicidad del ejercicio y disfrute del derecho, quedando otras facultades típicas de dominio, que podrán ejercitarse en cualquier momento, incluso durante el periodo de tiempo en que el disfrute material corresponde a otro multipropietario.

En resumen, no debemos confundir la periodicidad del ejercicio del derecho de multipropiedad, con la duración ilimitada del mismo, siendo inadmisible configurarla como un supuesto de propiedad temporal.

De otro lado, la Propiedad Dividida, existe cuando los aprovechamientos de una misma cosa pertenecen a dos o más personas, pero no de una forma alícuota o proporcional, como el condominio, sino perteneciendo a una persona unos aprovechamiento y a otra otros distintos. Se trata de una situación prodiviso, diferente a la propiedad pro indiviso de la copropiedad.

El planteamiento básico de la naturaleza jurídica de la multipropiedad, puede establecerse a partir de la idea que se trata de un supuesto de concurrencia de varios derechos cualitativamente iguales sobre una misma cosa o entidad física. El criterio adoptado para solucionar ese conflicto de intereses no es el de la atribución de distintos aprovechamientos materiales a uno y otro titular, sino un criterio meramente temporal mediante la atribución de períodos de tiempo, para el disfrute de todos los aprovechamientos que el objeto material puede tener. ${ }^{58}$

\section{Análisis y críticas}

Hay una semejanza con el condominio, desde que existe una pluralidad de sujetos que reunidos en torno a un mismo objeto, lo disfrutan de modo periódico e individual por periodos de tiempo anuales. El problema de equiparar el condominio a la Multipropiedad, es en la partición a la que tiene derecho los copropietarios en cualquier momento, el pacto de indivisión es de naturaleza transitorio, en cambio en la Multipropiedad la división del objeto por periodos de tiempo es un elemento esencial del sistema y no implica renuncia alguna, ya que el derecho no se extiende a más de un lapso al año.

${ }^{58}$ Allende SAlAZAR, Luis. Op. cit. p.93. 
En resumen, la Multipropiedad, se halla lejos de ser un supuesto del condominio, aún en el caso de regularlo bajo la indivisión forzosa perpetua, que tiene su sustento en la inservibilidad de la cosa para el fin creado, siendo la esencia de la figura de la copropiedad, su naturaleza transitoria.

Considero, que el adecuar la Multipropiedad a la figura de la copropiedad, no es el camino más propicio, el cambiar la esencia de una estructura jurídica completa para adecuarla a nuestras necesidades, no sería lo más conveniente, de alguna forma se estaría desnaturalizando dicha figura, siendo un instituto jurídico, con raíces profundas, tan importantes y trascendentales en las relaciones humanas.

Si así pensáramos, entonces nada nos costaría asimilar la Multipropiedad como un usufructo especial, el cual sabemos se caracteriza por ser vitalicio, pero por razones de darle un encuadre legal a la figura analizada, propondríamos que se regule un usufructo perpetuo y transmisible por acto inter vivos y mortis causa, o un hospedaje o derecho de habitación, que es un derecho real que nos permite usar un bien inmueble pero no podemos realizar sobre él ningún acto jurídico; acaso resolveríamos el problema de regular a la multipropiedad como supuesto de hospedaje especial, con la salvedad de incluir en su regulación la posibilidad de realizar cualquier acto jurídico entre vivos o mortis causa?

Considero que cualquier forma adoptada, desnaturalizaría las figuras con las que se le intenta regular, debido a que el fenómeno multipropietario nace como producto de la necesidad de contar con una segunda vivienda, donde poder disfrutar nuestras vacaciones, teniendo en cuenta que el estrés de la vida cotidiana, ha propiciado a que el individuo goce de un descanso reparador, como un derecho que nos asiste a todos, más aún si está protegido por la mayoría de las constituciones del mundo.

En la tesis Argentina, no han tomado en cuenta, el derecho de retracto que tienen los comuneros, lo que va, como ya lo señalara, contra el interés socio- económico del sistema, puesto que la propiedad, está cobrando un sentido social y no individualista como en el derecho romano.

Otro inconveniente que se observa, es lo referente a la administración del complejo turístico, ya que tratándose de titulares en su mayoría extranjeros, la Junta General de Propietarios que es el órgano máximo y que agrupa a todos los adquirentes del sistema, no cumpliría a cabalidad sus funciones primordiales, puesto que es característico de la copropiedad que las decisiones de disposición del bien, sean adoptadas por unanimidad.

Como vemos, sería casi imposible acudir a cada reunión que se realice, máxime si sólo contamos con unos días disponibles al año, que la utilizamos para el descanso vacacional, aunque cabe la salvedad de nombrar en el lugar de ubicación del complejo 
turístico, a un representante legal; todo esto desde ya, acarrearía molestias entre los adquirentes, quienes lo único que buscan es el descanso, haciendo uso de su periodo de tiempo sobre el inmueble afectado, dejando en manos del Administrador lo relacionado a asuntos propios del complejo.

En relación al promotor, no es una ventaja someter el sistema bajo la modalidad de la copropiedad, en virtud que vendiendo los porcentajes se desliga de responsabilidad y deja en manos de los adquirentes su futuro. Creo, más bien, y como se da en la mayoría de complejos sometidos a éste régimen, que el promotor se convierte luego de vender todas las cuotas, en que divide cada unidad funcional del complejo turístico, en el Administrador.

El Administrador, es la figura principal que hace posible que el sistema se mantenga, desarrolle, y tenga éxito; lo cual llevará a que sea bien visto por otros consumidores deseosos de adquirir una propiedad en tiempo compartido, ya que el fracaso en el funcionamiento del sistema, traería una mala reputación, haciendo que ésta gran iniciativa empresarial no sea difundida y con el tiempo desaparezca, lo que de ninguna manera convendrá a los intereses de los grandes capitalistas.

\section{Nuestra propuesta}

Después de un análisis exhaustivo de la presente figura, habiendo definido sus características y elementos, así como sus semejanzas y diferencias con otras instituciones jurídicas acogidas por nuestro ordenamiento jurídico nacional, se puede afirmar que la Multipropiedad se ha convertido en una figura que merece un tratamiento diferente, siendo necesario una regulación propia, que recoja todo el sistema que engloba ésta actividad de importante iniciativa empresarial.

Nuestro derecho Peruano, siguiendo los lineamientos del derecho Romano, concibe a la propiedad como el derecho de usar, disfrutar, disponer, y reinvindicar el bien sobre el cual recae nuestros derechos, siendo por tanto el instituto de la propiedad, el elemento estratégico de nuestro código civil, alrededor del cual aparecen otras instituciones que se relacionan, pero que no llegan a tener la calidad de ser un derecho absoluto.

Como lo señala Borda, la propiedad romana, caracterizada por ser individualista, ha evolucionado, convirtiéndose en una institución social, por el hecho de que más valor tiene el bienestar de todos, frente al bienestar de uno sólo.

Con ésta premisa y basados en la socialización de la propiedad es que me atrevo a considerar a la Multipropiedad, como un nuevo derecho real de propiedad, en donde el límite de mi derecho, como es tradicional, ya no será sólo el espacio, sino aparece otro elemento esencial y diferenciador, que es el tiempo. 
El tiempo, pues, se convertirá en la medida de mi derecho de propiedad, siendo por tanto un factor innovador, que no está incurso en ninguna figura jurídica regulada por nuestro derecho positivo, haciendo necesario su encuadre jurídico, a pedido de la sociedad, porque nuestra misión no es restringirlo o estatizarlo, sino darle viabilidad para que se desarrolle plenamente, respetando siempre el derecho de los demás y la constitución misma.

Como ocurre, la realidad se adelanta al derecho, y es función de éste normar las relaciones jurídicas entre los hombres, sin embargo, valdría la pena hacerse la siguiente reflexión ¿podemos encasillar dentro de una ley, la evolución de las relaciones humanas, que es tan dinámica y constantemente van cambiando o apareciendo nuevas situaciones de acuerdo a las necesidades, producto de las grandes transformaciones?

Considero que es muy difícil abarcar todo lo complejo que son las relaciones humanas, porque la realidad es más extensa que unas páginas escritas, pero no por ello, se debe dejar de dar, los lineamientos generales para que ambas partes contratantes no vean afectados sus derechos, o no se vean enfrascados por la superioridad de la otra parte.

Estos derechos de multipropiedad, se adquieren a través de contratos de adhesión, por ser múltiples los consumidores que desean adquirir el sistema y disfrutar de sus beneficios; de ello se deriva nuestro interés de dotar a dicha figura de todas las garantías frente a la sociedad.

La forma más adecuada de darle seguridad jurídica al consumidor adquirente, es mediante la configuración de la Multipropiedad como un nuevo derecho real, de tal manera que el que adquiera el sistema, tendrá la seguridad jurídica de gozar de un derecho absoluto y perpetuo, transmisible por acto inter vivos o mortis causa.

\section{La multipropiedad en el Perú}

\section{Decreto Supremo 032-82-ITI del 23 de Julio de 1982}

Se crea una nueva modalidad de establecimiento turístico denominado "Tiempo Compartido", los cuales se ubican dentro de lo que son los establecimientos de hospedaje. En su Art. 2do. Se refiere a los Establecimientos Turísticos de Tiempo Compartido como: "... aquellos que ceden a los usuarios el derecho de uso indefinido de las unidades inmobiliarias de dichos establecimientos, pudiendo ejercerse dicho derecho por periodos de tiempo determinados dentro de cada año calendario", acá se trata de la cesión del derecho de uso en forma indefinida por parte de los promotores del establecimiento respecto de los tiempo compartidores. 
En el Art. 3ro. "..Estarán dedicados única y exclusivamente para dar alojamiento con fines turísticos, "establece un vínculo fundamental de destino

En el Art. 4to., se regula la protección al consumidor, al obligar a los promotores a contar con las garantías debidas.

El Reglamento de Establecimientos de Hospedaje, conceptúa al Establecimiento Turístico de Tiempo Compartido como un supuesto de Hospedaje.

\section{Decreto legislativo 706 del 5 de noviembre de 1991}

En el Perú se ha regulado la Multipropiedad mediante este decreto, denominándola tiempo compartido. A través de ella se pretende fomentar la inversión turística, contribuyendo decididamente al turismo vacacional interno y receptivo, a la generación de empleo y a la captación de divisas. Establece la necesidad de regular legislativamente la modalidad de "tiempo Compartido" a fin de poder competir en igualdad de condiciones con los demás países del orbe en materia de turismo.

Conciben a la Multipropiedad como el bien inmueble destinado al use y goce vacacional, a través de la creación de una nueva modalidad de co-propiedad en la cual ya se encuentra regulado el uso y disfrute, mediante un contrato desde su origen. En dicho contrato se pacta una indivisión hasta por 30 años renovables.

Este decreto dispone la aplicación de las disposiciones del CC 84 relativas a la copropiedad con excepción de los artt. 983 al 991, 992 inc. 1 y 993 y demás disposiciones que se opongan al presente decreto.

Considero que la Multipropiedad se halla lejos de ser una forma de copropiedad, debido a que en la copropiedad los titulares son propietarios de todo el inmueble todo el tiempo, en la multipropiedad el adquirente es titular exclusivo sobre el inmueble delimitado a un periodo anual; siendo la diferencia más resaltante, que la Multipropiedad es un derecho perpetuo, mientras que la copropiedad es de naturaleza temporal, pudiendo cualquier copropietario pedir la partición del bien en cualquier momento, trayendo como consecuencia la inestabilidad del sistema, si se le pretende aplicar al fenómeno multipropietario.

Por las razones expuestas, es necesaria una regulación que permita desarrollar ésta figura jurídica, sobre todo teniendo en cuenta su trascendencia económica y social ya que ofrece beneficios tanto para los inversionistas como para el público consumidor. 


\section{BIBLIOGRAFÍA}

1. Alegre Carrión, José. Multipropiedad: Nuevo sistema para adquirir inmuebles. En El Peruano. Lima 4 de Mayo de 1995.

2. Allendesalazar Ormaechea, Luis, Álvarez Arza, Magdalena. El time-sharing, su configuración jurídica tributaria en España. Ministerio de Economía y Hacienda, Madrid 1987

3. Alterini, Jorge Horacio. Los Derechos Reales en el Proyecto del Código Civil Argentino. En el Código Civil del Siglo XXI. T. I, Ediciones Jurídicas, Lima, 2000.

4. Alterini, Jorge Horacio. El Numerus Clausus en los Derechos Reales. En Código Civil Peruano, Balance y Perspectivas. T.I, WG Editor EIRL, Universidad de Lima, 1995.

5. Avendaño V., Jorge. Derechos Reales. 2da. Edición. Lluvia Editores, Lima 1990.

6. Borda, Guillermo. Manual de Derechos Reales. 5ta. edición. Editorial Perrot, Buenos Aires, 2003.

7. Borda, Guillermo. Tendencias Actuales del Derecho de Propiedad. En Tendencias Actuales y Perspectivas del Derecho Privado y el Sistema Jurídico Latino Americano. Cultural Cuzco S.A., Lima 1988

8. Decreto Legislativo 706 del 5 de Noviembre de 1991.

9. Decreto Supremo 032-82-ITI del 23 de Julio de 1982.

10. Di Filippo, María Isabel. Tiempo Compartido. Un Condominio Especial. Abeledo-Perrot. Buenos Aires, 1987. 
11. Galo, Emanuele, y Corda, Antonio. La Multipropiedad. Editoriales de derecho reunidas. España, 1985.

12. García, Alfredo, landeta, Bernardo. Propiedad dividida y copropiedad "pro indiviso" en el código civil. En Centenario del Código Civil T. IV. Mariar S.A. Madrid, 1989.

13. Lovece, Graciela-Guersi, Carlos A. Contrato de Tiempo Compartido (Timesharing). Editorial Universidad, Buenos Aires, 2000.

14. Messineo, Francesco. Manual de Derecho Civil y Comercial. EJEA, Buenos Aires, 1979.

15. Morales Acosta, Gonzalo. La Multipropiedad Inmobiliaria-El Tiempo Compartido: una alternativa para la inversión privada. Asesorandina publicaciones. Lima, 1994. 